\title{
SIMULASI ALIRAN DAYA PADA PEMBANGKIT LISTRIK TENAGA MESIN GAS (PLTMG) BADAS UNTUK SISTEM KELISTRIKAN SUMBAWA BESAR MENGGUNAKAN SOFTWARE ETAP 16
}

\author{
Indra Darmawan 1) , Fuad Abdurrahman Rafif ${ }^{2)}$, Addien Wahyu Wiratama ${ }^{3)}$ \\ ${ }^{1,2)}$ Teknik Elektro Universitas Teknologi Smbawa \\ 3) PT PLN Persero \\ email :1) indra.darmawan@uts.ac.id, ${ }^{2)}$ Fuad.arafif@gmail.com
}

\begin{abstract}
Abstraksi
Sistem tenaga listrik merupakan proses dari pembangkitan energi listrik hingga penyaluran kepada pengguna. Sistem yang terintegrasi dengan baik memberikan jaminan mutu untuk keandalan sistem. Analisis dilakukan guna meminimalisir rugi-rugi penyaluran. Sistem kelistrikan Sumbawa Besar saat ini dalam proses peningkatan kapasitas penyaluran transmisi $150 \mathrm{KV}$ dengan PLTMG BADAS sebagai pusat pembangkitan terbesar. Penelitian dilakukan dengan menganalisis aliran daya pada PLTMG BADAS untuk sistem kelistrikan Sumbawa Besar yang ditinjau pada bus sistem $20 \mathrm{KV}$, dan dengan simulasi menggunakan software ETAP 16. Metode penelitian dilakukan dengan data berasal dari PLN Sumbawa dan analisis perhitungan aliran daya menggunakan metode Newton Raphson nilai presisi 0,0001. Simulasi dilakukan pada tiga skenario pembangkitan, yaitu: 1) Operasi 1 mesin PLTMG, 2) Operasi 2 mesin PLTMG, 3) Operasi seluruh mesin PLTMG. Ketiga skenario dilakukan pada kondisi operasi normal. Hasil simulasi menunjukkan bahwa analisis aliran daya dengan metode Newton-Raphson menghasilkan 2 kali iterasi pada setiap skenario, dan diperoleh parameter sebagai berikut: 1) Rata-rata nilai tegangan tertinggi pada skenario 1 sebesar 20,43 KV dengan sudut fasa -14,3,2) Total daya Aktif - Reaktif tertinggi pada skenario 2 sebesar 44,475 MW dan 9,557 MVAR, 3) Skenario 1 memiliki rugi-rugi daya terendah sebesar 2,634 MW dan 5,168 MVAR serta tegangan jatuh sebesar 2,275\%.
\end{abstract}

Kata Kunci :

Aliran Daya, Newton-Raphson, ETAP 16.

\section{Abstract}

Electric power system is a process of electrical energy generation to dispense to users. A well-integrated system provides quality assurance for system reliability. Analysis is conducted to minimize dispensing losses. The electrical system of Sumbawa Besar is currently in the process of upgrading $150 \mathrm{KV}$ transmission distribution capacity with PLTMG BADAS as the largest generation center. The research was conducted by analyzing the power flow on PLTMG BADAS for the electrical system of Sumbawa Besar which was reviewed on $20 \mathrm{KV}$ bus system, and by simulating using ETAP 16 software. The research method is done with data derived from Sumbawa's PLN and analysis of the power flow calculation using the method Newton-Raphson precision value 0.0001. The simulation is performed on three generation scenarios, namely: 1) Operation 1 PLTMG engine, 2) operation 2 PLTMG engines, 3) operation of the entire PLTMG machine. All three scenarios are done under normal operating conditions. Simulated results show that the analysis of power flows by Newton-Raphson method generates 2 iterations in each scenario, and the following parameters are obtained: 1) average of the highest voltage value in Scenario 1 OF $20.43 \mathrm{KV}$ With phase angle-14.3,2) Total active power - highest reactive in Scenario 2 of $44.475 \mathrm{MW}$ and 9.557 MVAR, 3) Scenario 1 has the lowest power loss of $2.634 \mathrm{MW}$ and 5.168 MVAR and voltage fall by $2.275 \%$.

Keywords :

Load Flow, Newton-Raphson, ETAP 16

\section{Pendahuluan}

Sistem tenaga listrik harus memiliki kualitas hasil produksi listrik yang konstan untuk memberikan jaminan pelayanan optimal kepada konsumen. Sistem yang terintegrasi dapat meningkatkan mutu serta keandalan agar memberikan nilai keamanan tinggi, bekerja efektif dan efisien dalam proses penyebarannya dan mampu menyediakan listrik dengan nilai ekonomis yang tinggi. Perusahaan Listrik Negara (PLN) Unit Pelaksana Pelayanan Pelanggan (UP3) Sumbawa sedang dalam pengembangan sistem kelistrikan 20 Kilo Volt (KV) menjadi $150 \mathrm{KV}$.

Sistem kelistrikan Sumbawa Besar memiliki Pembangkit Listrik Tenaga Mesin Gas (PLTMG) BADAS berkapasitas 50 Mega Watt (MW) dengan transmisi penyaluran sebesar $150 \mathrm{KV}$ Proses penyaluran sistem kelistrikan sering kali terjadi gangguan yang menyebabkan sebagian komponen tidak bekerja maksimal dan menyebabkan ketidakseimbangan yang dapat menghambat proses penyalurannya. Analisis studi aliran daya merupakan solusi untuk meminimalisir rugi-rugi penyaluran system yang sedang beroperasi. Analisis studi aliran 
daya dilakukan untuk mengetahui nilai tegangan, sudut fasa, daya aktif - reaktif, rugi-rugi daya (losses), dan tegangan.

Penelitian ini membahas tentang studi aliran daya pada PLTMG BADAS untuk sistem kelistrikan di Sumbawa Besar dengan menggunakan software Electric Transient and Analysis Program (ETAP) versi Power Station 16 untuk mempermudah proses simulasi dan perhitungan. Penelitian ini dapat memberikan masukan untuk perbaikan sistem terhadap skenario yang dilakukan. Penelitian ini diharapkan Memberikan hasil pembanding untuk perencanaan operasional serta pengembangan sistem agar dapat meningkatkan kualitas penyaluran listrik pada PLTMG BADAS untuk sistem kelistrikan Sumbawa Besar

\section{Tinjauan Pustaka}

Ervan dan Taufiq (2012) melakukan penelitian Analisis Aliran Daya pada Sistem Tenaga Listrik 150 KV Gorontalo menggunakan Metode Newton Raphson. Hasil penelitian diperoleh informasi berupa daya aktif yang harus dibangkitkan oleh unit pembangkit sudah melebihi daya mampu pasok dan kapasitas beban terpasang. Pemenuhan pelayanan yang baik kepada konsumen sebagai pedoman dalam pengoperasian sistem tenaga listrik, perencanaan pengembangan sistem, dan juga sebagai dasar untuk studi lainya seperti koordinasi relay proteksi, analisis transien, maupun studi stabilitas dan keandalan sistem [1].

Menurut Sudirham (2012), salah satu cara untuk mengirimkan energi dengan ekonomis, mudah dan aman adalah melalui bentuk energi listrik. Energi listrik secara kontinyu dapat dikirimkan dari satu tempat ke tempat lain dengan jarak berjauhan dalam suatu sistem tenaga listrik. Sistem tenaga listrik merupakan kumpulan dari komponen-komponen atau alat-alat listrik seperti generator, transformator, saluran transmisi, saluran distribusi, dan beban, yang dihubungkan membentuk suatu sistem[2].

\section{Study Aliran Daya}

tegangan dan arus untuk pernyataan fasor pada perhitungan daya yang dapat diselesaikan dalam bentuk bilangan kompleks. Besaran daya kompleks dinyatakan sebagai $\mathrm{S}$.

$S=|V| .|I| \cos (\alpha-\beta)+j|V| .|I| \sin (\alpha+\beta)$ Karena $\alpha-\beta$, sudut fasa antara tegangan dengan arus adalah $\theta$

$$
S=P+j Q
$$

Daya reaktif $Q$ akan positif bila sudut fasa $\alpha-\beta$ antara tegangan dan arus itu positif, bila $\alpha>\beta$ berarti arus tertinggal dari tegangannya. Sebaliknya, $Q$ negatif untuk $\alpha<\beta$ dengan arus mendahului tegangannya. Hal itu sesuai dengan pemilihan tanda positif untuk daya reaktif pada beban induktif dan tanda negatif untuk daya reaktif pada beban kapasitif.

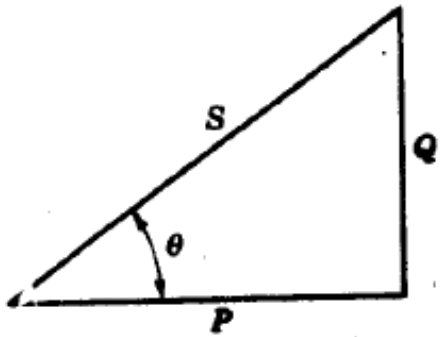

Persamaan 2.2 menunjukkan suatu cara untuk memperoleh $P, Q$ dan sudut fasa keseluruhan bagi beberapa beban yang dihitung paralel karena $\cos \theta$ adalah $P / S \mid$. Sebuah segitiga daya untuk beban induktif, untuk beberapa beban yang dihubung paralel, daya $P$ keseluruhan merupakan jumlah daya pada beban, yang merupakan sumbu panjang mendatar dalam suatu analisa grafis, untuk suatu beban induktif, $Q$ sumbu tegak ke atas merupakan nilai $Q$ positif dan beban kapasitif akan mempunyai daya reaktif yang negatif dengan $Q$ mengarah ke bawah [3].

Analisis aliran daya pada sistem tenaga listrik memiliki ketentuan-ketentuan sebagai berikut [4]:

- Sistem dalam keadaan seimbang; dengan demikian kita dapat melakukan perhitungan dengan menggunakan model satu-fasa.

- Semua besaran dinyatakan dalam per-unit;

$$
\begin{aligned}
P_{i}=-P_{G i}+P_{L i} & +\sum_{j=1}^{n}\left|V_{i}\right|\left|Y_{i j}\right|\left|V_{j}\right| \cos \left(\delta_{i}-\delta_{j}\right. \\
& \left.-\delta_{i j}\right)=0 \\
Q_{i}=-Q_{G i}+Q_{L i} & +\sum_{j=1}^{n}\left|V_{i}\right|\left|Y_{i j}\right|\left|V_{j}\right| \sin \left(\delta_{i}-\delta_{j}\right. \\
& \left.-\delta_{i j}\right)=0
\end{aligned}
$$

\section{Metode Newton Repshon}

Metode Newton-Raphson adalah Metode yang paling sering digunakan untuk menyelesaikan suatu sistem persamaan nonlinier, metode Newton-Raphson menggunakan teknik iteratif. Teknik iteratif ini merupakan pencarian solusi yang dimulai dengan estimasi awal untuk variabel yang ingin dicari. Estimasi tersebut kemudian diperbaiki secara berturutan sampai solusi yang diinginkan diperoleh. Apabila solusinya telah didapat, maka dikatakan bahwa solusinya telah konvergen.

Berikut adalah penjelasan mengenai penggunaan Metode tersebut pada sistem persamaan nonlinier umum. Misalkan persamaan nonlinier dengan jumlah persamaan $n$ diberikan oleh [5]:

$F(X)=\left[\begin{array}{c}f_{1}\left(x_{1}, x_{2}, \ldots, x_{n}\right) \\ f_{2}\left(x_{1}, x_{2}, \ldots, x_{n}\right) \\ \vdots \\ f_{n}\left(x_{1}, x_{2}, \ldots, x_{n}\right)\end{array}\right]=0$

$X=\left[x_{1}, x_{2}, \ldots, x_{n}\right]^{T}$ adalah variabel yang akan dicari. Langkah iteratif dari Metode Newton-Raphson dalam mencari solusi adalah dengan menyelesaikan persamaan berikut secara berturutan :

$X^{(k+1)}=X^{(k)}+\Delta X^{(k)}$

Dimana 
$\Delta X^{(k)}=-\left[J\left(X^{(k)}\right]^{-1} F\left(X^{(k)}\right)\right.$

Persamaan 2.7, $J(X)$ merupakan Jacobian dari $F(X)$ dan dihitung melalui:

$J(X)=\left[\begin{array}{cccc}\frac{\partial f_{1}}{\partial x_{1}} & \frac{\partial f_{1}}{\partial x_{2}} & \cdots & \frac{\partial f_{1}}{\partial x_{n}} \\ \frac{\partial f_{2}}{\partial x_{1}} & \frac{\partial f_{2}}{\partial x_{2}} & \cdots & \frac{\partial f_{2}}{\partial x_{n}} \\ \vdots & \vdots & \ddots & \vdots \\ \frac{\partial f_{n}}{\partial x_{1}} & \frac{\partial f_{n}}{\partial x_{2}} & \cdots & \frac{\partial f_{n}}{\partial x_{n}}\end{array}\right]$

\section{ETAP Power Station 16}

Electric Transient and Analysis Program (ETAP) versi Power Station 16 merupakan salah satu Software yang digunakan untuk mensimulasikan sistem tenaga listrik. Analisa sistem tenaga listrik yang dapat dilakukan antara lain yaitu, analisa aliran daya, hubung singkat, arc flash, starting motor, koordinasi proteksi, kestabilan transien, dll.

Suatu diagram saluran tunggal atau Single Line Diagram (SLD) sistem tenaga listrik tiga fasa memudahkan pembacaan diagram dan analisa rangkaian. Elemen elektrik seperti misalnya generator, pemutus, transformator, busbar, beban statis dan konduktor lain dapat ditunjukkan dengan menggunakan simbol yang telah distandardisasi untuk SLD [6].

\section{Metode Penelitian}

Penelitian ini berdasarkan studi kasus di sistem kelistrikan sumbawa :

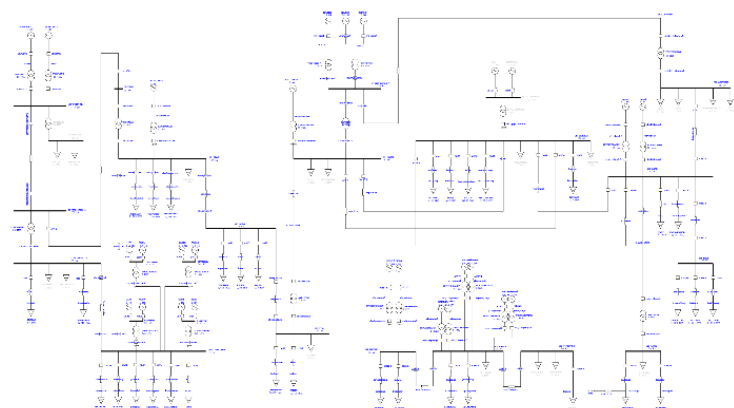

Gambar 2. Single line diagram kelistrikan sumbawa Metode pada penelitian ini menggunakan metode newton repshon dalam menganalisis aliran daya, yang disimulasikan melalui program ETAP 16. Penelitian mengembangkan tiga sekernario dalam proses simulasi yaitu, pertama Penggunaan PLTMG 1, PLTU 1 dan 2, BPSA 1 dan 2, BGP Empang dengan total daya pasok $47 \mathrm{MW}$.

Tabel 1. Sekernario pertama

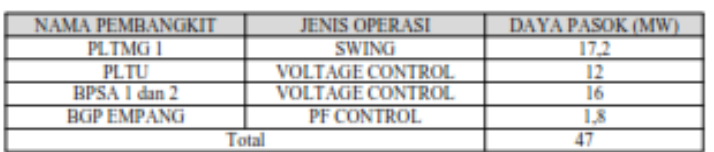

Sekernario kedua Penggunaan PLTMG 2-3, PLTU 1 dan 2, BPSA 1, BGP EMPANG dengan total daya pasok 47,2 MW:

Tabel 2. Sekernario 2

\begin{tabular}{|c|c|c|}
\hline NAMA & JENIS OPERASI & DAYA PASOK (MW) \\
\hline PEMBANGIT & SWING & 24,6 \\
\hline PL.TMG 2 DAN 3 & VOLTAGECONTROL & 12 \\
\hline PLTU 1 DAN 2 & VOLTAGECONTROL & 8 \\
\hline BPSA I & PF CONTROL & 26 \\
\hline BGPEMPANG & TOTALL & 47.2 \\
\hline
\end{tabular}

sekenario 3 Penggunaan seluruh mesin PLTMG, PLTU dan BGP EMPANG dengan total daya pasok 47 MW.

Tabel 3. Sekernario 3

\begin{tabular}{|c|c|c|}
\hline NAMA & JENIS OPERASI & DAYA PASOK (MW) \\
\hline PEMBANGIT & SWING & 32 \\
\hline PLTMG & VOLTAGE CONTROL & 12 \\
\hline PLTU & PF CONTROL & 3 \\
\hline BGPEMPANG & TOTAL & 47 \\
\hline
\end{tabular}

\section{Hasil dan Pembahasan}

Sekenario pertama

Simulasi skenario 1 diperoleh hasil perhitungan studi aliran daya dengan tingkat presisi pada iterasi ke-2, dan diketahui parameter sebagai berikut:

- Tegangan dan Sudut fasa

\begin{tabular}{|c|c|c|c|}
\hline \multirow{2}{*}{ BUS } & \multicolumn{3}{|c|}{ Tegangan Bus } \\
\cline { 2 - 4 } & $\begin{array}{c}\text { Nilai } \\
\text { Tegangan } \\
(\%)\end{array}$ & $\begin{array}{c}\text { Sudut } \\
\text { Fasa }\end{array}$ & $\begin{array}{c}\text { Nilai } \\
\text { Tegangan } \\
(\mathrm{KV})\end{array}$ \\
\hline GH ALAS & 101,136 & $-24,9$ & 20,2272 \\
\hline GH BOAK & 102,436 & $-6,1$ & 20,4872 \\
\hline GH EMPANG & 98,186 & -12 & 19,6372 \\
\hline GH LABUHAN & 100,5 & $-8,5$ & 20,1 \\
\hline GH LAPE & 101,99 & $-8,9$ & 20,398 \\
\hline GH MOYO & 99,717 & $-7,7$ & 19,9434 \\
\hline GH & 100,776 & $-10,1$ & 20,1552 \\
PLAMPANG & 104,587 & $-14,4$ & 20,9174 \\
\hline GH UTAN & 102,229 & $-26,8$ & 20,4458 \\
\hline GI ALAS & 99,609 & $-11,4$ & 19,9218 \\
\hline GI EMPANG & 106,905 & $-4,9$ & 21,381 \\
\hline GI LABUHAN & 102,709 & $-27,9$ & 20,5418 \\
\hline GI TALIWANG & 104,807 & $-8,1$ & 20,9614 \\
\hline GI BADAS & 100,303 & $-28,7$ & 20,0606 \\
\hline PLTD TLW & & 20,36985714 \\
\hline \multicolumn{2}{|c|}{ Rata-rata } &
\end{tabular}

- Daya Aktif dan Reaktif

\begin{tabular}{|c|c|c|c|c|}
\hline \multicolumn{5}{|c|}{ Daya Aktif - Reaktif } \\
\hline \multirow{3}{*}{ Dari } & Ke & P (MW) & Q (MVAR) & $\begin{array}{c}\text { PF } \\
(\%)\end{array}$ \\
\hline & GH UTAN & $-4,954$ & 2,651 & $\begin{array}{c}- \\
88,2\end{array}$ \\
\cline { 2 - 5 } & GI ALAS & 2,27 & $-2,757$ & - \\
63,6 \\
\hline \\
\cline { 2 - 5 } & GH MOYO & 2,606 & 0,573 & 97,7 \\
\cline { 2 - 5 } & GI LABUHAN & $-2,947$ & $-1,748$ & 86 \\
\cline { 2 - 5 } & GH LAPE & 4,277 & 0,158 & 99,9 \\
\cline { 2 - 5 } & & 4,714 & $-0,58$ & - \\
& GH LABUHAN & 4,714 & $-0,58$ & - \\
\cline { 2 - 5 } & & $-1,128$ & $-0,384$ & 94,7 \\
\hline GH BOAK EMPANG & GI EMPANG & $-1,961$ & $-2,208$ & 66,4 \\
\hline GH LABUHAN & GI BADAS & & \multicolumn{2}{c}{} \\
\hline
\end{tabular}




\begin{tabular}{|c|c|c|c|c|}
\hline & & $-1,939$ & $-2,282$ & 64,8 \\
\hline & \multirow{2}{*}{ GH BOAK } & $-4,598$ & 0,758 & $\begin{array}{c}- \\
98,7\end{array}$ \\
\hline & & $-4,598$ & 0,758 & $\begin{array}{c}- \\
98,7\end{array}$ \\
\hline GH LAPE & GH BOAK & $-4,261$ & 0,05 & 100 \\
\hline GH MOYO & GH BOAK & $-2,551$ & $-0,488$ & 98,2 \\
\hline GH PLAMPANG & GI EMPANG & 1,68 & $-0,131$ & $\begin{array}{c}- \\
99,7 \\
\end{array}$ \\
\hline \multirow{2}{*}{ GH UTAN } & GH ALAS & 5,538 & $-1,758$ & $\begin{array}{c}- \\
95,3 \\
\end{array}$ \\
\hline & GI BADAS & $-9,955$ & 1,121 & $\begin{array}{c}- \\
99,4\end{array}$ \\
\hline \multirow[b]{2}{*}{ GI ALAS } & GH ALAS & $-2,203$ & 2,86 & -61 \\
\hline & PLTD TLW & 1,357 & $-0,069$ & $\begin{array}{c}- \\
99,9\end{array}$ \\
\hline \multirow[t]{2}{*}{ GI EMPANG } & GH PLAMPANG & $-1,657$ & 0,165 & $\begin{array}{c}- \\
99,5 \\
\end{array}$ \\
\hline & GH EMPANG & 1,14 & 0,403 & 94,3 \\
\hline GI LABUHAN & GH BOAK & 3,038 & 1,886 & 85 \\
\hline GI TALIWANG & PLTD TLW & 5,075 & 2,683 & 88,4 \\
\hline \multirow{3}{*}{ GI BADAS } & GH UTAN & 10,039 & $-0,029$ & 100 \\
\hline & \multirow{2}{*}{ GH LABUHAN } & 2,031 & 2,315 & 66 \\
\hline & & 2,008 & 2,392 & 64,3 \\
\hline \multirow[b]{2}{*}{ PLTD TLW } & GI TALIWANG & $-4,991$ & $-2,554$ & 89 \\
\hline & GI ALAS & $-1,328$ & 0,113 & $\begin{array}{c}- \\
99,6 \\
\end{array}$ \\
\hline
\end{tabular}

\begin{tabular}{|c|c|c|c|}
\cline { 2 - 3 } $\begin{array}{c}\text { GI } \\
\text { EMPANG }\end{array}$ & 100,9 & $-14,8$ & 20,18 \\
\hline $\begin{array}{c}\text { GI } \\
\text { LABUHAN }\end{array}$ & 108 & -5 & 21,6 \\
\hline $\begin{array}{c}\text { GI } \\
\text { TALIWANG }\end{array}$ & 102,8 & $-28,1$ & 20,56 \\
\hline GI BADAS & 105,8 & $-8,5$ & 21,16 \\
\hline PLTD TLW & 100,4 & $-28,8$ & 20,08 \\
\hline \multicolumn{3}{|c|}{ Rata-rata } & 20,43 \\
\hline
\end{tabular}

- Rugi - rugi daya dan tegangan jatuh

\begin{tabular}{|c|c|c|c|c|c|}
\hline \multirow{2}{*}{ Saluran } & \multicolumn{2}{|c|}{ Rugi-rugi Daya } & \multicolumn{2}{|c|}{$\begin{array}{c}\text { Tegangan Bus } \\
\text { (\%) }\end{array}$} & \multirow{2}{*}{$\begin{array}{c}\text { Vd } \\
\text { (\%) }\end{array}$} \\
\cline { 2 - 5 } & $\mathbf{P}(\mathbf{k W})$ & $\begin{array}{c}\mathbf{Q} \\
\text { (kVAR) }\end{array}$ & Dari & Ke & \\
\hline EXPALAS & 583,9 & 892,6 & 101,1 & 104,6 & 3,45 \\
\hline EXPTANO & 67,4 & 892,6 & 101,1 & 102,2 & 1,09 \\
\hline EXPMOYO & 55 & 84,1 & 102,4 & 99,7 & 2,72 \\
\hline KOPELKOTA & 90,7 & 138,7 & 102,4 & 106,9 & 4,47 \\
\hline EXPLAPE & 16 & 207,6 & 102,4 & 102 & 0,45 \\
\hline EXPBOAK & 116,2 & 177,7 & 102,4 & 100,5 & 1,95 \\
\hline EXPBOAK2 & 116,2 & 177,7 & 102,4 & 100,5 & 1,95 \\
\hline KOPELEMPANG & 12 & 18,3 & 98,2 & 99,6 & 1,42 \\
\hline EXPKANAR & 70 & 107 & 100,5 & 104,8 & 4,31 \\
\hline EXPPLTMG & 68,6 & 110,1 & 100,5 & 104,8 & 4,31 \\
\hline EXPPLAMPANG & 22,7 & 34,6 & 100,8 & 99,6 & 1,17 \\
\hline EXPUTAN & 83,9 & 1091,1 & 104,6 & 104,8 & 0,22 \\
\hline SETELUK & 28,6 & 43,8 & 102,2 & 100,3 & 1,93 \\
\hline EXPTALIWANG & 84,4 & 129,1 & 102,8 & 100,3 & 2,41 \\
\hline
\end{tabular}

Daya Aktif dan Reaktif

\begin{tabular}{|c|c|c|c|c|}
\hline \multicolumn{5}{|c|}{ Daya Aktif - Reaktif } \\
\hline Dari & ke & $P(M W)$ & Q (MVAR) & PF (\%) \\
\hline \multirow{2}{*}{ GH ALAS } & GH UTAN & $-5,003$ & 2,49 & $-89,5$ \\
\hline & GI ALAS & 2,301 & $-2,596$ & $-66,3$ \\
\hline \multirow{5}{*}{ GH BOAK } & GH MOYO & 2,562 & 0,563 & 97,7 \\
\hline & GI LABUHAN & $-6,392$ & $-0,903$ & 99 \\
\hline & GH LAPE & 3,562 & $-0,402$ & $-99,4$ \\
\hline & \multirow{2}{*}{ GH LABUHAN } & 2,853 & $-0,411$ & -99 \\
\hline & & 2,853 & $-0,411$ & -99 \\
\hline $\begin{array}{c}\text { GH } \\
\text { EMPANG }\end{array}$ & GI EMPANG & $-1,157$ & $-0,394$ & 94,7 \\
\hline \multirow{4}{*}{$\begin{array}{c}\text { GH } \\
\text { LABUHA } \\
\mathbf{N}\end{array}$} & \multirow{2}{*}{ GI BADAS } & $-3,724$ & $-1,907$ & 89 \\
\hline & & $-3,733$ & $-2,016$ & 88 \\
\hline & \multirow{2}{*}{ GH BOAK } & $-2,809$ & 0,477 & 81,9 \\
\hline & & $-2,809$ & 0,477 & 81,9 \\
\hline GH LAPE & GH BOAK & $-3,55$ & 0,55 & $-98,8$ \\
\hline $\begin{array}{l}\text { GH } \\
\text { MOYO }\end{array}$ & GH BOAK & $-2,508$ & $-0,48$ & 98,2 \\
\hline GH & & & & \\
\hline $\begin{array}{c}\text { PLAMPA } \\
\text { NG }\end{array}$ & GI EMPANG & 0,961 & $-0,658$ & $-82,5$ \\
\hline \multirow{2}{*}{ GH UTAN } & GH ALAS & 5,577 & $-1,613$ & $-96,1$ \\
\hline & GI BADAS & $-10,064$ & 0,965 & $-99,5$ \\
\hline \multirow{2}{*}{ GI ALAS } & GH ALAS & $-2,237$ & 2,693 & $-63,9$ \\
\hline & PLTD TLW & 1,373 & $-0,046$ & $-99,9$ \\
\hline \multirow{2}{*}{$\begin{array}{c}\text { GI } \\
\text { EMPANG } \\
\end{array}$} & GH PLAMPANG & $-0,951$ & 0,675 & $-81,6$ \\
\hline & GH EMPANG & 1,17 & 0,413 & 94,3 \\
\hline $\begin{array}{c}\text { GI } \\
\text { LABUHA } \\
\mathbf{N}\end{array}$ & GH BOAK & 6,719 & 1,404 & 97,9 \\
\hline $\begin{array}{c}\mathbf{G l} \\
\text { TALIWAN } \\
\mathbf{G}\end{array}$ & PLTD TLW & 5,073 & 2,665 & 88,5 \\
\hline \multirow{3}{*}{$\begin{array}{c}\text { GI } \\
\text { BADAS }\end{array}$} & GH UTAN & 10,148 & 0,129 & 100 \\
\hline & \multirow{2}{*}{ GH LABUHAN } & 3,864 & 2,122 & 87,7 \\
\hline & & 3,871 & 2,238 & 86,6 \\
\hline \multirow{2}{*}{$\begin{array}{l}\text { PLTD } \\
\text { TLW }\end{array}$} & GI TALIWANG & $-4,989$ & $-2,537$ & 89,1 \\
\hline & GI ALAS & $-1,343$ & 0,091 & $-99,8$ \\
\hline
\end{tabular}

Sekenario Kedua

- Tegangan dan Sudut fasa

\begin{tabular}{|c|c|c|c|}
\hline \multirow{2}{*}{ BUS } & \multicolumn{3}{|c|}{ Tegangan Bus } \\
\cline { 2 - 4 } & $\begin{array}{c}\text { Rating } \\
\text { Tegangan } \\
(\%)\end{array}$ & Sudut Fasa & $\begin{array}{c}\text { Nilai Tegangan } \\
\text { (KV) }\end{array}$ \\
\hline GH ALAS & 101,5 & $-25,1$ & 20,3 \\
\hline GH BOAK & 101,6 & $-8,7$ & 20,31 \\
\hline $\begin{array}{c}\text { GH } \\
\text { EMPANG }\end{array}$ & 99,44 & $-15,5$ & 19,89 \\
\hline $\begin{array}{c}\text { GH } \\
\text { LABUHAN }\end{array}$ & 100,4 & $-10,2$ & 20,08 \\
\hline GH LAPE & 101,8 & $-11,1$ & 20,36 \\
\hline GH MOYO & 98,88 & $-10,3$ & 19,78 \\
\hline $\begin{array}{c}\text { GH } \\
\text { PLAMPANG }\end{array}$ & 100,8 & $-13,9$ & 20,17 \\
\hline GH UTAN & 105,4 & $-14,7$ & 21,08 \\
\hline GI ALAS & 102,4 & $-26,9$ & 20,48 \\
\hline
\end{tabular}

- Rugi - rugi daya dan tegangan jatuh

\begin{tabular}{|c|c|c|c|c|c|}
\hline \multirow{2}{*}{ Saluran } & \multicolumn{2}{|c|}{ Rugi-rugi Daya } & \multicolumn{2}{c|}{ Tegangan Bus (\%) } & \multirow{2}{*}{$\begin{array}{c}\text { Vd } \\
\text { (\%) }\end{array}$} \\
\cline { 2 - 5 } & $\mathbf{P}(\mathbf{k W})$ & $\mathbf{Q}(\mathbf{k V A R})$ & Dari & $\mathbf{K e}$ & $\mathbf{3}$ \\
\hline EXPALAS & 573,7 & 877 & 101,5 & 101,4 & 3,94 \\
\hline EXPTANO & 63,2 & 96,6 & 101,5 & 102,4 & 0,94 \\
\hline EXPMOYO & 54,1 & 82,7 & 101,6 & 98,8 & 2,7 \\
\hline KOPELKOTA & 327,5 & 500,6 & 101,6 & 108 & 6,44 \\
\hline EXPLAPE & 11,4 & 148,1 & 101,6 & 101,8 & 0,24 \\
\hline EXPBOAK & 43,5 & 66,5 & 101,6 & 100,4 & 1,15 \\
\hline EXPBOAK2 & 43,5 & 66,5 & 101,6 & 100,4 & 1,15 \\
\hline KOPELEMPANG & 12,3 & 18,7 & 99,4 & 100,9 & 1,44 \\
\hline EXPKANAR & 140,7 & 215,1 & 100,4 & 105,8 & 5,4 \\
\hline EXPPLTMG & 137,9 & 221,2 & 100,4 & 105,8 & 5,4 \\
\hline EXPPLAMPANG & 10,8 & 16,5 & 100,8 & 100,9 & 0,05 \\
\hline EXPUTAN & 84,1 & 1093,9 & 105,4 & 105,8 & 0,4 \\
\hline SETELUK & 29,2 & 44,6 & 102,4 & 100,4 & 2 \\
\hline EXPTALIWANG & 84 & 128,4 & 102,8 & 100,4 & 2,4 \\
\hline
\end{tabular}


Sekenario Ketiga

- Tegangan dan Sudut fasa

\begin{tabular}{|c|c|c|c|}
\hline \multirow[b]{2}{*}{ BUS } & \multicolumn{3}{|c|}{ Tegangan Bus } \\
\hline & $\begin{array}{c}\text { Rating } \\
\text { Tegangan } \\
(\%)\end{array}$ & $\begin{array}{c}\text { Sudu } \\
\text { t } \\
\text { Fasa }\end{array}$ & $\begin{array}{c}\text { Nilai } \\
\text { Tegangan } \\
(\mathbf{K V})\end{array}$ \\
\hline GH ALAS & 101,5 & $-25,2$ & 20,3 \\
\hline GH BOAK & 99,47 & $-11,1$ & 19,89 \\
\hline $\begin{array}{c}\text { GH } \\
\text { EMPANG }\end{array}$ & 99,71 & $-17,3$ & 19,94 \\
\hline $\begin{array}{c}\text { GH } \\
\text { LABUHAN } \\
\end{array}$ & 99,24 & $-11,6$ & 19,85 \\
\hline GH LAPE & 100,1 & $-13,3$ & 20,02 \\
\hline GH MOYO & 96,83 & $-12,7$ & 19,37 \\
\hline $\begin{array}{c}\text { GH } \\
\text { PLAMPAN } \\
\text { G }\end{array}$ & 100,5 & $-15,8$ & 20,09 \\
\hline GH UTAN & 105,5 & $-14,9$ & 21,11 \\
\hline GI ALAS & 102,4 & -27 & 20,49 \\
\hline $\begin{array}{c}\text { GI } \\
\text { EMPANG }\end{array}$ & 101,2 & $-16,6$ & 20,23 \\
\hline $\begin{array}{c}\text { GI } \\
\text { LABUHAN }\end{array}$ & 108,3 & $-4,7$ & 21,65 \\
\hline $\begin{array}{c}\text { GI } \\
\text { TALIWANG }\end{array}$ & 102,8 & $-28,2$ & 20,56 \\
\hline GI BADAS & 106 & $-8,7$ & 21,19 \\
\hline PLTD TLW & 100,4 & $-28,9$ & 20,09 \\
\hline & ata-rata & & 20,34 \\
\hline
\end{tabular}

- Daya Aktif dan Reaktif

\begin{tabular}{|c|c|c|c|c|}
\hline \multicolumn{5}{|c|}{ Daya Aktif - Reaktif } \\
\hline Dari & Ke & $\mathbf{P}(\mathbf{M W})$ & $\begin{array}{c}\mathbf{Q} \\
(\mathbf{M V} \\
\mathbf{A R})\end{array}$ & PF (\%) \\
\hline \multirow{2}{*}{$\begin{array}{c}\text { GH } \\
\text { ALAS }\end{array}$} & GH UTAN & $-5,01$ & 2,468 & $-89,7$ \\
\hline & GI ALAS & 2,305 & $-2,575$ & $-66,7$ \\
\hline \multirow{5}{*}{$\begin{array}{c}\text { GH } \\
\text { BOAK }\end{array}$} & $\begin{array}{c}\text { GH } \\
\text { MOYO }\end{array}$ & 2,457 & 0,54 & 97,7 \\
\hline & $\begin{array}{c}\text { GI } \\
\text { LABUHA } \\
\mathbf{N}\end{array}$ & $-9,77$ & $-0,123$ & 100 \\
\hline & GH LAPE & 3,101 & $-0,721$ & $-97,4$ \\
\hline & \multirow{2}{*}{$\begin{array}{c}\text { GH } \\
\text { LABUHA } \\
\mathbf{N} \\
\end{array}$} & 0,892 & $-0,301$ & $-94,7$ \\
\hline & & 0,892 & $-0,301$ & $-94,7$ \\
\hline $\begin{array}{c}\text { GH } \\
\text { EMPAN } \\
\text { G } \\
\end{array}$ & $\begin{array}{c}\text { GI } \\
\text { EMPANG }\end{array}$ & $-1,164$ & $-0,396$ & 94,7 \\
\hline \multirow{4}{*}{$\begin{array}{c}\text { GH } \\
\text { LABUH } \\
\text { AN }\end{array}$} & \multirow{2}{*}{ GI BADAS } & $-5,478$ & $-1,686$ & 95,6 \\
\hline & & $-5,517$ & $-1,831$ & 94,9 \\
\hline & \multirow{2}{*}{ GH BOAK } & $-0,887$ & 0,309 & $-94,5$ \\
\hline & & $-0,887$ & 0,309 & $-94,5$ \\
\hline $\begin{array}{c}\text { GH } \\
\text { LAPE }\end{array}$ & GH BOAK & $-3,092$ & 0,843 & $-96,5$ \\
\hline $\begin{array}{c}\text { GH } \\
\text { MOYO }\end{array}$ & GH BOAK & $-2,405$ & $-0,461$ & 98,2 \\
\hline $\begin{array}{c}\text { GH } \\
\text { PLAMP } \\
\text { ANG } \\
\end{array}$ & $\begin{array}{c}\text { GI } \\
\text { EMPANG }\end{array}$ & 0,581 & $-0,935$ & $-52,8$ \\
\hline \multirow{2}{*}{$\begin{array}{l}\text { GH } \\
\text { UTAN }\end{array}$} & GH ALAS & 5,582 & $-1,593$ & $-96,2$ \\
\hline & GI BADAS & $-10,078$ & 0,944 & $-99,6$ \\
\hline \multirow{2}{*}{$\begin{array}{c}\text { GI } \\
\text { ALAS }\end{array}$} & GH ALAS & $-2,242$ & 2,671 & $-64,3$ \\
\hline & $\begin{array}{l}\text { PLTD } \\
\text { TLW } \\
\end{array}$ & 1,375 & $-0,043$ & -100 \\
\hline \multirow{2}{*}{$\begin{array}{c}\text { GI } \\
\text { EMPAN } \\
\quad \text { G }\end{array}$} & $\begin{array}{c}\text { GH } \\
\text { PLAMPA } \\
\text { NG }\end{array}$ & $-0,571$ & 0,95 & $-51,5$ \\
\hline & $\begin{array}{c}\text { GH } \\
\text { EMPANG }\end{array}$ & 1,176 & 0,415 & 94,3 \\
\hline
\end{tabular}

\begin{tabular}{|c|c|c|c|c|}
\hline $\begin{array}{c}\text { GI } \\
\text { LABUH } \\
\text { AN }\end{array}$ & GH BOAK & 10,552 & 1,319 & 99,2 \\
\hline $\begin{array}{c}\text { GI } \\
\text { TALIW } \\
\text { ANG }\end{array}$ & $\begin{array}{l}\text { PLTD } \\
\text { TLW }\end{array}$ & 5,073 & 2,663 & 88,5 \\
\hline \multirow{3}{*}{$\begin{array}{c}\text { GI } \\
\text { BADAS }\end{array}$} & GH UTAN & 10,162 & 0,15 & 100 \\
\hline & \multirow{2}{*}{$\begin{array}{c}\text { GH } \\
\text { LABUHA } \\
\mathbf{N}\end{array}$} & 5,749 & 2,099 & 93,9 \\
\hline & & 5,782 & 2,256 & 93,2 \\
\hline \multirow[t]{2}{*}{$\begin{array}{l}\text { PLTD } \\
\text { TLW }\end{array}$} & $\begin{array}{c}\text { GI } \\
\text { TALIWA } \\
\text { NG } \\
\end{array}$ & $-4,989$ & $-2,535$ & 98,2 \\
\hline & GI ALAS & $-1,345$ & 0,088 & $-99,8$ \\
\hline
\end{tabular}

- Rugi - rugi daya dan tegangan jatuh

\begin{tabular}{|c|c|c|c|c|c|}
\hline \multirow{2}{*}{ Saluran } & \multicolumn{2}{|c|}{$\begin{array}{c}\text { Rugi-rugi } \\
\text { Daya }\end{array}$} & \multicolumn{2}{c|}{$\begin{array}{c}\text { Tegangan Bus } \\
(\mathbf{\%})\end{array}$} & \multirow{2}{*}{$\begin{array}{c}\text { Vd } \\
(\mathbf{\%})\end{array}$} \\
\cline { 2 - 5 } & $\mathbf{P}(\mathbf{k W})$ & $\begin{array}{c}\mathbf{Q} \\
\mathbf{k V} \\
\mathbf{A R} \\
\mathbf{n}\end{array}$ & $\mathbf{D a r i}$ & $\mathbf{K e}$ & \\
\hline EXPALAS & 572,4 & 875 & 101,5 & 105,5 & 4 \\
\hline EXPTANO & 62,6 & 95,7 & 101,5 & 102,4 & 0,92 \\
\hline EXPMOYO & 51,9 & 79,3 & 99,5 & 96,8 & 2,64 \\
\hline KOPELKOTA & 782,3 & $\begin{array}{c}119 \\
5,9\end{array}$ & 99,5 & 108,3 & 8,79 \\
\hline EXPLAPE & 9,4 & $\begin{array}{c}121, \\
9\end{array}$ & 99,5 & 100,1 & 0,65 \\
\hline EXPBOAK & 4,8 & 7,4 & 99,5 & 99,2 & 0,23 \\
\hline EXPBOAK2 & 4,8 & 7,4 & 99,5 & 99,2 & 0,23 \\
\hline KOPELEMPANG & 12,3 & 18,8 & 99,7 & 101,2 & 1,45 \\
\hline EXPKANAR & 270,5 & $\begin{array}{c}413, \\
5\end{array}$ & 99,2 & 106 & 6,72 \\
\hline EXPPLTMG & 265 & $\begin{array}{c}425, \\
2\end{array}$ & 99,2 & 106 & 6,72 \\
\hline EXPPLAMPANG & 9,7 & 14,9 & 100,5 & 101,2 & 0,7 \\
\hline EXPUTAN & 84,2 & $\begin{array}{c}109 \\
4,3\end{array}$ & 105,5 & 106 & 0,43 \\
\hline SETELUK & 29,2 & 44,7 & 102,4 & 100,4 & 2,01 \\
\hline EXPTALIWANG & 83,9 & $\begin{array}{c}128, \\
3\end{array}$ & 102,8 & 100,4 & 2,39 \\
\hline & & & &
\end{tabular}

\section{Pembahasan}

Hasil dari nilai tegangan pada masing-masing skenario tersebut dapat dilihat pada grafik Gambar 3 berikut:

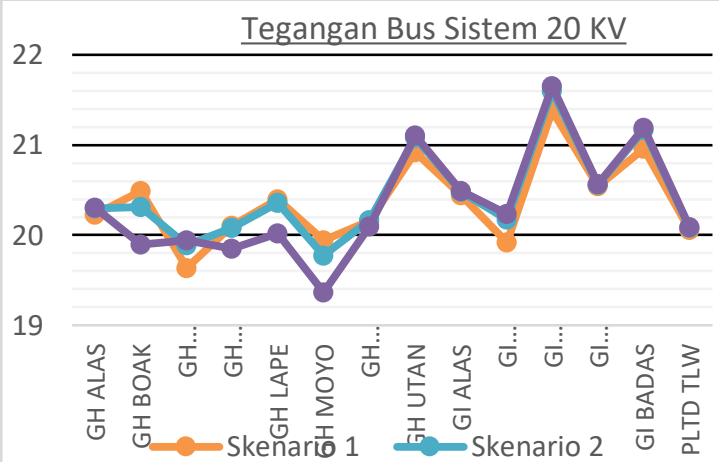

Gambar 3. Nilai tegangan pada setiap sekenario

Nilai tegangan tertinggi pada masing-masing skenario terdapat pada bus GI LABUHAN yaitu untuk skenario 1 sebesar 21,38 KV, untuk skenario 2 sebesar 21,6 KV, dan untuk skenario 3 sebesar 21,65 $\mathrm{KV}$. Sedangkan, nilai tegangan terendah terdapat pada bus GH MOYO pada skenario 3 sebesar 19,37 
KV dibandingkan dengan skenario 1 dan 2 yang memiliki nilai tegangan terendah lebih dari 19,5 KV. Total rugi-rugi daya aktif - reaktif yang terdapat pada masing-masing skenario diperoleh nilai sebagai berikut (Lampiran 2, 3, dan 4. Hasil Report Branch Losses Summary):

Skenario 1 sebesar 2633,8 kW dan 5168,3 kVAR. Skenario 2 sebesar 2810,5 kW dan 5771,7 kVAR. Skenario 3 sebesar 3436,2 kW dan 6976,2 kVAR. Grafik perbandingan total daya aktif dan reaktif terhadap 3 skenario dapat dilihat pada Gambar 4 Berikut :

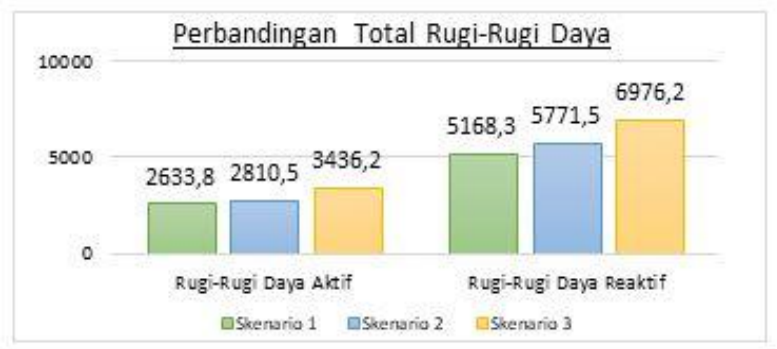

Berdasarkan grafik perbandingan pada Gambar 4.9, diperoleh hasil bahwa skenario 1 memiliki jumlah rugi-rugi daya aktif dan reaktif paling sedikit dibandingkan dengan skenario 2 dan 3 . Nilai tegangan jatuh terbesar berada pada skenario 3 yaitu mencapai $8,79 \%$, dan tegangan jatuh terkecil berada pada skenario 1 sebesar $4,47 \%$.

\section{Kesimpulan dan Saran}

Kesimpulan yang didapatkan dari hasil simulasi program ETAP 16 untuk studi aliran daya dan gangguan hubung singkat 3 fasa pada penelitian ini adalah:

- Analisis studi aliran daya menggunakan metode Newton-Raphson menghasilkan kecepatan proses perhitungan dengan nilai presisi 0,0001 hanya 2 kali iterasi untuk setiap skenario. Adapun hasil analisis terhadap parameter yang dicari sebagai berikut :

- Nilai Tegangan dan Sudut Fasa pada skenario 1 memiliki rata-rata nilai tegangan tertinggi sebesar 20,43 KV dengan sudut fasa $-14,3$.

- Daya aktif - reaktif yang mengalir pada skenario 2 memiliki total tertinggi sebesar 44,475 MW dan 9,557 MVAR.

- Rugi-rugi daya dan tegangan jatuh pada skenario 1 memiliki rugi-rugi daya terendah sebesar 2,634 MW dan 5,168 MVAR, serta rata-rata tegangan jatuh sebesar $2,275 \%$.

\section{Daftar Pustaka}

[1] Harun, Yusuf. 2012. Analisis Aliran Daya pada Sistem Tenaga Listrik $150 \mathrm{KV}$ Gorontalo menggunakan Metode Newton
Raphson. Gorontalo: Universitas Negeri Gorontalo.

[2] Sudirham, Sudaryatno. Juli 2012. Analisa Sistem Tenaga. Bandung: Darpublic.

[3] Saadat, Hadi. 1999. Power System Analysis. New York: McGraw-Hill Book Co.

[4] Djalal, Haikal. 2014. Penyelesaian Aliran Daya 37 Bus dengan Metode Newton Raphson (Studi Kasus Sistem Interkoneksi $150 \mathrm{KV}$ Sulawesi Selatan) Makassar: Politeknik Ujung Pandang.

[5] Sulistiyono, Dwi. 2011. Perbandingan Metode Gauss-Siedel, Metode Newton Raphson, dan Metode Fast Decoupled dalam Solusi Aliran Daya. Semarang: Univ. Diponegoro.

[6] Multa, Lesnanto. 2013. Modul Pelatihan ETAP; ETAP 11. Yogyakarta: Universitas Gadjah Mada. 